\title{
Investigation on the Clinical Readiness of Nurses' Evidence-Based Practice in a 3A-Level General Hospital in Beijing
}

\author{
Luo YANG ${ }^{1}$, Hong GUO ${ }^{1, *}$, Yan-Ling SHEN² Li LI $^{2}$, You-Hua LIU ${ }^{1}$, Dan ZHAO ${ }^{1}$, Hai-Yan WANG ${ }^{1}$, \\ Shao-Hua GONG ${ }^{1}$, Xiao-Ping $\mathrm{YI}^{1}$ \\ ${ }^{1}$ School of Nursing, Beijing University of Chinese Medicine, Beijing 100029, China; \\ ${ }^{2}$ China-Japan Friendship Hospital, Beijing 100029, China
}

\begin{abstract}
Objective: To understand the evidence-based practice readiness of developing evidence application projects in a 3A-level general hospital in Beijing, to identify barriers to evidence-based practice and to promote the successful application of evidence.

Methods: All the clinical nurses who were going to participate in the application units of the evidence-based practice project were selected as the survey objects, and the self-made "Basic Information Questionnaire" and "Clinical Readiness to Evidence-based Nursing Assessment (CREBNA)" were used to conduct the survey. The total amounts and subscales were calculated. The factors that influence the score of the total scale were scored and analyzed.

Results: The CREBNA total score was (119.87 \pm 19.18$)$, the evidence subscale score was $(47.94 \pm 8.54)$, the organizational environmental subscale score was (36.09 \pm 6.11$)$, and the facilitator subscale score was (35.83 \pm 7.56$)$. Univariate analysis showed that the total score of the scale was related to years of work, scientific research experience, knowledge of evidence-based care, and participation in evidence-based practice.

Conclusion: The current evidence-based practice preparation situation is good. It is feasible to carry out evidence-based practice activities in the hospital. The follow-up development plan should be made based on the corresponding obstacle factors.
\end{abstract}

Key words: Readiness for evidenced-based practice; Evidence-based nursing; Evidence application

\section{Introduction}

Evidence-based health care is the core guiding ideology of the $21^{\text {st }}$ century, with the aim of emphasizing that clinical practice should be based on the best evidence. The

*Corresponding Author:

Hong GUO, School of Nursing, Beijing University of Chinese Medicine, Beijing 100029, China E-mail: guohong2015@I63.com.

Received: March 31 2019, Revised:April 8 2019,Accepted:April 10 2019, Online: May 152019 application of evidence is the application of evidencebased evidence to practical activities, which is marked by changes in practices or systems (management systems, processes, norms, standards, etc. $)^{[1]}$. This process may be affected by many factors ${ }^{[2]}$, and many obstacles may lead to the failure of evidence-based practice 
activities $^{[3]}$. Evidence-based practice readiness refers to the psychological, behavioral, and structural readiness of the entire organization, members, and environment during the implementation of evidence-based practice activities by medical personnel ${ }^{[4]}$. The assessment of organizational readiness can not only predict the likelihood of successful change before the resource is invested, but also promote the success of organizational change by identifying and overcoming the obstacles to change ${ }^{[2]}$. This study intends to use the "Clinical Readiness to Evidence-based Nursing Assessment (CREBNA)" to investigate the 5units of the China-Japan Friendship Hospital that are about to carry out evidence-based practice activities. The relevant factors affecting the evidence-based practice readiness scores in the evidence application project are identified, and the obstacle factors that may be faced in the implementation process are identified to develop a personalized intervention strategy to promote evidence conversion.

\section{Materials and Methods}

\section{Data collection}

This study was approved by the ethics committee of Beijing University of Chinese Medicine. The data collection was carried out by cluster sampling method, and all the nurses in the 5 intensive care units, including the Surgical Intensive Care Unit (SICU), the Internal Intensive Care Unit (IICU), the Emergency Intensive Care Unit (EICU), the Cardiac Intensive Care Unit (CCU) and the Neurology Unit of the China-Japan Friendship Hospital. Inclusion criteria: All registered nurses participating in the evidence application project; nurses volunteered to participate in the study and signed informed consent. The characteristics of the research objects were shown in Table 1.

\section{Research tools}

Basic Information Questionnaire: The Basic Information Questionnaire is designed by the researcher to obtain the general information of the registered nurses. The content includes gender, age, working years, job title, professional title, scientific research experience, evidence-based practice understanding, the necessity and significance of conducting evidence-based practice, etc.
Table 1Characteristics of the research objects $(n=169)$

\begin{tabular}{|c|c|c|}
\hline Characteristics & Number & Percentage (\%) \\
\hline \multicolumn{3}{|l|}{ Units } \\
\hline SICU & 52 & 30.77 \\
\hline IICU & 54 & 31.95 \\
\hline $\mathrm{CCU}$ & 23 & 13.61 \\
\hline EICU & 21 & 12.43 \\
\hline Neurology Unit & 19 & 11.24 \\
\hline \multicolumn{3}{|l|}{ Gender } \\
\hline Male & 11 & 6.51 \\
\hline Female & 158 & 93.49 \\
\hline \multicolumn{3}{|l|}{ Educational level } \\
\hline Specialist & 10 & 5.92 \\
\hline Bachelor & 157 & 92.90 \\
\hline Master's degree & 2 & 1.18 \\
\hline \multicolumn{3}{|l|}{ Job title } \\
\hline Nurse & 140 & 82.84 \\
\hline Clinical teacher & 6 & 3.55 \\
\hline Clinical leader & 18 & 10.65 \\
\hline Head nurse & 5 & 2.96 \\
\hline \multicolumn{3}{|l|}{ Professional title } \\
\hline Senior nurse & 18 & 10.65 \\
\hline Junior nurse & 119 & 70.41 \\
\hline Primary nurse and above & 32 & 18.93 \\
\hline \multicolumn{3}{|c|}{ Scientific research experiences } \\
\hline Have & 59 & 34.91 \\
\hline Not & 110 & 65.09 \\
\hline \multicolumn{3}{|c|}{ Evidence-based understanding } \\
\hline Have not heard & 20 & 11.83 \\
\hline Heard about it & 35 & 20.71 \\
\hline Learn some & 100 & 59.17 \\
\hline More understanding & 14 & 8.28 \\
\hline \multicolumn{3}{|c|}{ Participated in evidence-based training } \\
\hline Yes & 50 & 29.59 \\
\hline No & 119 & 70.41 \\
\hline
\end{tabular}

CREBNA scale: The scale is used to assess the readiness of current evidence-based practice projects. Designed by Huang Miao and others from Fudan University's evidencebased nursing center, the scale is the first evidence-based nursing practice preparation assessment tool in China ${ }^{[5]}$. The tool is based on a literature analysis of the Promoting Action on Research in Health Services (PARIHS) model ${ }^{[6]}$ and interviews and is formed through a rigorous scale programming process. The scale includes the evidence subscale, the organizational environment subscale, and the 
facilitator subscale, for a total of 31 items. The evidence subscale has a total of 12 items, which is the evaluation of the sense of identity and applicability in the evidencebased practice $^{[7]}$; the organizational environment subscale includes a total of 9 items, mainly used to assess the leadership and organizational culture in the evidencebased practice environment ${ }^{[8]}$; the facilitator subscale contains 10 items that are used to assess the individual, team, and management level drivers that drive evidencebased practices in the application of evidence. Taking the 5-point Likert scale, 1 point represents complete nonconformity, 5 points represents complete compliance, and higher score indicates that the item are better prepared in the current clinical situation, which is more conducive to the development of the current evidence application project. This indicates that the current unit has poor acceptability of the best evidence to be applied, and the resistance to the current evidence application project is high. The Cronbach's $\alpha$ coefficient of the total scale is 0.959 , the Cronbach's $\alpha$ coefficients of the 3 subscales are $0.940,0.933$ and 0.915 , the split-half reliability is 0.978 , and the test-retest reliability is 0.917 .

Survey method: Before conducting the evidencebased practice readiness assessment, ensure that all caregivers who are about to participate in the evidence application are trained in the implementation of the system's project, including the formation of the practice plan, the implementation strategy, and duration. Before the questionnaire is issued, the researcher will explain the purpose, the significance of the research and the test content in the form of a group. After obtaining the informed consent of the respondent, the questionnaire will be issued and filled out independently. The unclear explanation will be explained by the researchers themselves. The questionnaire were collected on the spot. Invalid questionnaire standard: (1) The questionnaire presents the same options for items. (2) Select multiple answers for the same item. (3) Missing items.

\section{Statistical analysis}

The data were entered and sorted using SAS 9.2 statistical software, double-checked, and the score of each item was described by mean \pm standard deviation (SD) $(\bar{x} \pm s)$. The $t$-test was used for comparison between subgroups. Oneway analysis of variance was used for comparison among subgroups. The single factor analysis of CREBNA total score was performed. Multivariate analysis was performed using multiple linear regression analysis. $P<0.05$ was considered statistically significant.

\section{Results}

\section{Basic situation}

A total of 175 questionnaires were distributed and recycled, of which, 169 questionnaires was valid, with an effective rate of $96.57 \%$. Among the respondents, 158 were women, accounting for $93.49 \%$, and 11 were men, accounting for $6.51 \%$. The average working time was 8.24 years.

\section{CREBNA score}

The total score of all items in the scale was (119.35 $20.30)$ points. In the 3 subscales, the score of the facilitator subscale was lower than $(35.83 \pm 7.56)$ points, as shown in Table 3.

\section{Single factor analysis of CREBNA scores}

Univariate analysis showed that the total score of the scale was related to years of work, scientific research experience, knowledge of evidence-based care, and participation in evidence-based practice (Table 4).

\section{Factors affecting CREBNA scores}

The total score of the evidence-based practice preparation metric was the dependent variable. The general data of the clinical nurses surveyed were independent variables, and the disordered multi-class variable set the dummy variable. The introduction standard was 0.05 and the rejection criterion was 0.10 . The independent variable assignment was shown in Table 5. The results of multiple linear regression analysis were shown in Table 6.

\section{Discussion}

At present, there is a general lack of evaluation of evidence-based practice preparation before the application of evidence ${ }^{[9]}$, which leads to the lack of identification and coping strategies for the relevant obstacles of the entire 
Table 3 CREBNA scores situation

\begin{tabular}{|c|c|c|}
\hline Items & Score (points, $\bar{x} \pm s$ ) & Orders \\
\hline Evidence subscale (12 items) & $47.94 \pm 8.54$ & \\
\hline 1 The sources of these evidences are reliable. & $4.08 \pm 0.85$ & 4 \\
\hline 2 These evidences are assessed through a rigorous quality assessment process. & $4.01 \pm 0.83$ & 8 \\
\hline $\begin{array}{l}3 \text { These evidences are appropriate for patients/health care providers in institutions that are about } \\
\text { to implement evidence-based practices. }\end{array}$ & $4.01 \pm 0.81$ & 9 \\
\hline $\begin{array}{l}4 \text { The screening of these evidences combines the work experience and professional judgment of } \\
\text { clinical nurses. }\end{array}$ & $3.99 \pm 0.88$ & 12 \\
\hline 5 Screening of these evidences takes into account the needs of patients. & $3.91 \pm 0.87$ & 19 \\
\hline $\begin{array}{l}6 \text { The application of these evidences can promote patient recovery and directly or indirectly } \\
\text { improve patient outcomes. }\end{array}$ & $3.96 \pm 0.81$ & 16 \\
\hline 7 The implementation of these evidences can improve the quality of medical/nursing services. & $4.01 \pm 0.81$ & 10 \\
\hline 8 These evidences do not violate national policies and laws and regulations. & $4.21 \pm 0.87$ & 1 \\
\hline $\begin{array}{l}9 \text { The screening of these evidences takes into account current medical conditions and medical } \\
\text { standards. }\end{array}$ & $3.94 \pm 0.83$ & 17 \\
\hline $\begin{array}{l}10 \text { These evidences address the issue of the scope of medical/nursing duties and are able to } \\
\text { intervene in a corresponding manner. }\end{array}$ & $3.98 \pm 0.84$ & 13 \\
\hline $\begin{array}{l}11 \text { I am willing to accept this evidence for clinical use, which is in line with my self- } \\
\text { requirements and values. }\end{array}$ & $4.02 \pm 0.82$ & 7 \\
\hline $\begin{array}{l}12 \text { These evidences have been translated into forms that are easy to disseminate and useful } \\
\text { for understanding and application, such as the formation of processes, practice manuals, and } \\
\text { program posters. }\end{array}$ & $3.83 \pm 0.86$ & 21 \\
\hline Organizational Environment Subscale (9 items) & $36.09 \pm 6.11$ & \\
\hline 13 Leaders are good at actively exploring and improving clinical work. & $4.00 \pm 0.84$ & 11 \\
\hline 14 The leader has a good influence and we are willing to implement her/his advice or order. & $3.98 \pm 0.80$ & 14 \\
\hline 15 Leaders can reasonably allocate human resources based on clinical work. & $3.88 \pm 0.85$ & 20 \\
\hline 16 Leaders have good communication and coordination skills. & $4.04 \pm 0.78$ & 6 \\
\hline 17 Leaders can listen to our opinions and opinions widely. & $3.96 \pm 0.84$ & 15 \\
\hline 18 I am willing to try new clinical care processes, methods, techniques, etc. & $4.11 \pm 0.79$ & 3 \\
\hline 19 I have a good execution of the tasks assigned by my superiors. & $4.12 \pm 0.75$ & 2 \\
\hline 20 Our team members can work together to achieve specific goals. & $4.08 \pm 0.77$ & 5 \\
\hline 21 My ward has a culture of multidisciplinary collaboration and work processes. & $3.92 \pm 0.81$ & 18 \\
\hline Promoting factor subscale (10 items) & $35.83 \pm 7.56$ & \\
\hline $\begin{array}{l}22 \text { Evidence-based practice teams have promoters with extensive expertise and clinical } \\
\text { experience. }\end{array}$ & $3.78 \pm 0.83$ & 22 \\
\hline $\begin{array}{l}23 \text { Evidence-based practice teams have facilitators who have the authority to coordinate the } \\
\text { allocation of caregivers and related resources. }\end{array}$ & $3.75 \pm 0.85$ & 23 \\
\hline $\begin{array}{l}24 \text { Evidence-based practice teams have facilitators who can develop practical and feasible } \\
\text { evidence-based practices. }\end{array}$ & $3.75 \pm 0.84$ & 24 \\
\hline $\begin{array}{l}25 \text { I have organized, participated in, and collaborated on other research projects (including } \\
\text { evidence-based practice projects). }\end{array}$ & $3.05 \pm 1.22$ & 31 \\
\hline $\begin{array}{l}26 \text { The forthcoming evidence-based practice has been incorporated into all relevant personnel } \\
\text { (eg researchers, doctors, nurses and other multidisciplinary team members). }\end{array}$ & $3.52 \pm 0.93$ & 28 \\
\hline $\begin{array}{l}27 \text { There are incentive policies (such as job prospects, learning opportunities, collective honors, } \\
\text { rewards, etc.). }\end{array}$ & $3.50 \pm 0.98$ & 30 \\
\hline $\begin{array}{l}28 \text { There are training courses in various forms related to evidence-based practice projects (such } \\
\text { as lectures, video lectures, seminars, and practice exercises). }\end{array}$ & $3.50 \pm 1.00$ & 29 \\
\hline $\begin{array}{l}29 \text { The forthcoming/completed evidence-based practice project is supported by superior leaders } \\
\text { (hospital/care unit). }\end{array}$ & $3.74 \pm 0.91$ & 25 \\
\hline $\begin{array}{l}30 \text { There is a feedback system that optimizes the practice based on clinical nurses and patient } \\
\text { feedback. }\end{array}$ & $3.64 \pm 0.92$ & 26 \\
\hline $\begin{array}{l}31 \text { There are plans to promote evidence-based practice (to extend current evidence to other } \\
\text { hospitals/wards). }\end{array}$ & $3.60 \pm 0.96$ & 27 \\
\hline Total score & $119.87 \pm 19.18$ & \\
\hline
\end{tabular}


Table 4 Single factor analysis of CREBNA scores

\begin{tabular}{|c|c|c|c|}
\hline Characteristics & Score (points, $\bar{x} \pm s$ ) & $F / t$ & $P$ value \\
\hline Unit & & 2.27 & 0.0642 \\
\hline SICU & $120.44 \pm 15.88$ & & \\
\hline MICU & $116.35 \pm 22.46$ & & \\
\hline $\mathrm{CCU}$ & $125.48 \pm 19.75$ & & \\
\hline EICU & $118.00 \pm 17.35$ & & \\
\hline Neurology Unit & $123.58 \pm 18.10$ & & \\
\hline Gender & & 0.09 & 0.9300 \\
\hline Male & $120.36 \pm 20.93$ & & \\
\hline Female & $119.84 \pm 19.13$ & & \\
\hline Working years & & 1.65 & $0.0492^{*}$ \\
\hline$<9$ & $122.61 \pm 17.89$ & & \\
\hline$\geq 9$ & $117.93 \pm 19.91$ & & \\
\hline Educational level & & 0.73 & 0.3952 \\
\hline Specialist & $110.30 \pm 16.19$ & & \\
\hline Bachelor & $120.46 \pm 19.20$ & & \\
\hline Master's degree & $121.00 \pm 31.11$ & & \\
\hline Job title & & -0.82 & 0.4158 \\
\hline Head nurse/Clinical leader/Clinical teacher & $122.52 \pm 21.73$ & & \\
\hline Nurse & $119.32 \pm 18.65$ & & \\
\hline Professional title & & 1.34 & 0.2646 \\
\hline Senior nurse & $120.33 \pm 15.91$ & & \\
\hline Junior nurse & $118.51 \pm 18.85$ & & \\
\hline Primary nurse and above & $124.66 \pm 21.72$ & & \\
\hline Scientificresearch experiences & & 2.18 & $0.0304^{*}$ \\
\hline Have & $124.22 \pm 18.96$ & & \\
\hline Not & $117.54 \pm 18.98$ & & \\
\hline Evidence-based understanding & & 3.31 & $0.0293^{*}$ \\
\hline More understanding & $123.57 \pm 17.42$ & & \\
\hline Learn some & $122.61 \pm 20.02$ & & \\
\hline Heard about it & $117.09 \pm 14.07$ & & \\
\hline Have not heard & $108.45 \pm 20.09$ & & \\
\hline Participation in evidence-based practice & & 2.51 & $0.0130^{*}$ \\
\hline Yes & $125.50 \pm 17.84$ & & \\
\hline No & $117.50 \pm 19.31$ & & \\
\hline
\end{tabular}

Note: refers to $P<0.05$ and was considered statistically significant.

practice project before the implementation of evidencebased practice, leading to evidence-based nursing practice. The development is very challenging and makes employees feel a sense of change ${ }^{[10]}$. The assessment of the readiness of evidence-based practice helps identify many influencing factors before the application of the evidence, select the best interventions, and promote the translation of evidence ${ }^{[11]}$. The results of this study showed that the score of the total scale was $(119.87 \pm 19.18)$ points, accounting for $77.42 \%$ of the full score, indicating that the current preparation of evidence-based nursing practice is better. It is feasible to carry out the "Evidence-Based Practice Plan for Physical Constraints".

\section{The collective participation of nurses is conducive to the development of the project}

In this study, item 12 scored the lowest. In this evidence application project, the evidence summary was translated 
Table 5 Independent variable assignment of CREBNA scores influencing factors

\begin{tabular}{ll}
\hline Characteristics & Assignment method \\
\hline Unit & SICU $=0 ;$ MICU $=1 ;$ CCU $=2 ;$ EICU=3; Neurology Unit $=4$ \\
Gender & Male $=0 ;$ Female $=1$ \\
Working years & $<9=0 ; \geq 9=1$ \\
Educational level & Specialist $=0 ;$ Bachelor $=1 ;$ Master's degree and above $=2$ \\
Job title & Head nurse/Clinical leader $/$ Clinical teacher $=0 ;$ Nurse $=1$ \\
Professional title & Senior nurse $=0 ;$ Junior nurse $=1 ;$ Primary nurse and above $=2$ \\
Scientific research experiences & Have $=0 ;$ Not $=1$ \\
Evidence-based understanding & More understanding $/$ Learn some $=0 ;$ Heard about it $=1 ;$ Have not heard $=2$ \\
Participation in evidence-based practice & Yes $=0 ;$ No $=1$ \\
\hline
\end{tabular}

Table 6 Multiple linear regression analysis of factors affecting CREBNA score

\begin{tabular}{lccc}
\hline Characteristics & Regression coefficient & $\boldsymbol{t}$ & $\boldsymbol{P}$ value \\
\hline Working years & -4.02 & -2.21 & 0.0401 \\
Educational level & 8.51 & 8.46 & 0.0342 \\
Scientific research experiences & -5.87 & -2.60 & 0.0132 \\
Evidence-based understanding & -6.07 & -2.87 & 0.0047 \\
Participation in evidence-based training & -6.55 & -2.01 & 0.0462 \\
\hline
\end{tabular}

into a nursing process, a complete nursing program was formed, and nurses were trained. However, clinical nurses as implementers may, in most cases, only mechanically perform the processes and superior arrangements, and lack of in-depth thinking on practical activities ${ }^{[12]}$, so there is a lack of contrast between the resulting care plan and the best evidence. Some scholars have pointed out that when members of the organization can participate in the decisionmaking of change, the acceptance and compliance of change is higher ${ }^{[13]}$. To further reflect on this issue, we can see that members of the organization must have original potential, expertise, relevant knowledge resources, and opportunities to successfully implement organizational change. The ability of team members to activate their original potential depends on the availability of relevant professional knowledge, resources, and opportunities. The evidencebased practice process is a complex process of innovation. In this process, everyone needs collective coordination, andeveryonehas to change. Make an important contribution. In layman's terms, the important thing in this process is neither what I think I can do, nor what I think you can do, but what we think we can do together.

\section{The spirit of innovation is conducive to the application of evidence}

In the environmental organization subscale, the ranking of the scores of the 4 items is higher in the total amount table, indicating that the nurses have higher recognition of leaders and team culture. Among them, items 18, 19, and 20 scored higher. Nurses believe that they are willing to try new nursing procedures and are willing to cooperate with team members, indicating that nurses are willing to try new ideas in their work, and they are more willing to complete the tasks assigned by their superiors. Active organizational culture and team member relationship harmony are conducive to the development of practice change. The organizational culture that is innovative, adventurous, and learning can provide a good soil for evidence ${ }^{[14]}$. Item 15 "Leader can reasonably allocate human resources according to clinical work" has a low score. In China, the actual situation of most hospitals is that the nursing staff is seriously lacking. The bed protection ratio of many hospital wards is lower than the national standard $(1: 0.4)^{[15]}$. From each step of evidencebased nursing, it can be seen that the nursing staff require a large amount of time and energy during the complete evidence-based nursing implementation and evaluation process, so the nurses' concerns about human resources are not negligible in the process of conducting evidencebased nursing in China ${ }^{[16]}$.

\section{High-level nursing education and continuing}




\section{education training are conducive to evidence- based development}

In this study, the scores of the 22,25 , and 28 items indicated that the nurses felt that the clinical nursing work was busy and there were fewer approaches and opportunities to participate in relevant education and training. Therefore, they felt powerless when practicing evidence-based nursing. The results of multivariate analysis showed that the level of education of clinical nurses was directly proportional to the score of evidencebased practice preparation. That is to say, nurses with higher education level had better recognition and acceptance of evidence. These highly educated nurses may play an active role in the development of evidence-based practice projects. The KTA model proposes to develop an effective action strategy: providing education and training and skills guidance, and providing operational tools for the practitioner level ${ }^{[17]}$ to promote the translation of evidence into practice. Education is an important way for nursing staff to build professional expertise and professional skills, to maintain the level of competence, and to improve their practical ability ${ }^{[18-19]}$. Some scholars have proposed to improve professional skills and continuous competence through lifelong learning ${ }^{[20]}$. In the stage of evidence translation, under the strong support of the organization and the effective allocation of resources, through team training and other methods, as well as continuous evaluation, revision and verification of the program, we can truly implement the change, improve the patient's outcomes and the knowledge, behavior and attitude of the nurses. Finally, the benign operation of the system and continuous development are achieved ${ }^{[2]]}$.

\section{Research-based nursing stuff assists in the development of evidence-based nursing programs}

Univariate analysis showed that there were statistical differences in research experience, knowledge of evidence-based care, and participation in evidencebased practice. Through multiple regression analysis, the above items are directly proportional to the evidencebased practice readiness score. This means that nurses who have scientific research experience and who have learned or even participated in evidence-based training have maintained a great interest and support for evidencebased practice, and their evidence-based practice is better prepared. These nurses can act as a booster in the process of evidence-based projects. Working years is also statistically different from each other. Nurses with a working life of less than 9 years have higher scores, which may be related to the development of nursing education in China, and the deep-rooted concept of care have formed over the years. The nursing education received by the long-term nursing staff is usually biased towards the care of the disease, and the subjective willingness of the patient is neglected. The younger-aged nurses receive a better and more innovative nursing education, and are more able to accept new care concepts at work. There were no statistical differences in the scores of other respondents in this study, which may be related to insufficient total sample size or severe sample size bias. It is recommended that follow-up studies should expand the sample size in later studies and apply the scale to multiple evidence applications.

\section{Conclusions}

In summary, before the implementation of the evidencebased practice project, understanding the preparation of the project development unit and actively adopting effective strategies can promote the orderly, reasonable and humanized development of the project, and improve the evidence-based nursing level of clinical nurses. This can help clinical nurses to provide patients with more humanized quality care services and promote the overall level of care.

\section{Author Contributions}

Luo YANG and Hong GUO designed this research. YanLing SHEN and Li LI contributed to the later stages of the design. Luo YANG, You-Hua LIU, Dan ZHAO, HaiYan WANG, Shao-Hua GONG, Xiao-Ping YI collected and analyzed the data. All the authors gave suggestions to the data analysis and helped to interpret the results. Luo YANG completed the writing of this paper. All the authors read and approved the final manuscript. 


\section{Declaration}

The authors of this article declare no conflict of interest.

\section{Acknowledgments}

The authors gratefully acknowledge the 169 nurses who volunteered to participate in the study, as well as the administrator of the hospital who agreed to conduct this survey, and distribute the questionnaire to participants.

\section{References}

1 Alan P, Rick W, Anthea C, et a1. The JBI model of evidence-based healthcare. Int J Evid Based Health, 2005, 3(8): 207-215.

2 Gale BV, Schaffer MA. Organizational readiness for evidence-based practice. J Nurs Admin, 2009, 39(2): 91.

3 Dalheim A, Harthug S, Nilsen RM, et al. Factors influencing the development of evidence-based practice among nurses: a self-report survey. BMC Health Serv Res, 2012, 12(1): 367-367.

4 Klein KJ, Sorra JS. The Challenge of Innovation Implementation. Acad Manage Rev, 1996, 21(4): 1055-1080.

5 Huang Miao, Gu Ying, Zhang Yuxia, et al. Development and reliability evaluation of evidencebased nursing practice readiness assessment scale. Chin J Evid-Based Pediatr, 2017, 12(2): 121 -125.

6 Huang Miao, Gu Wei. Analysis of the literature category of the core elements of PARIHS model evolution and development. Nurs J Chin People's Liber Army, 2016, 33 (20): 1-5.

7 Li Y, Yu J, Du L, et al. Exploration and practice of methods and processes of evidence-based rapid review on peer review of WHO EML application. J Evid-Based Med, 2015, 8(4): 222-228.

8 Stetler CB, Damschroder LJ, Helfrich CD, et al. A Guide for applying a revised version of the PARIHS framework for implementation. Implement Sci, 2011, 6(1): 99-99.

9 Zhong Wei, Zhou Yingfeng. Methodology and application progress of implementation research. Chin
J Nurs, 2018, 53 (7): 862-866.

10 Nilsen P, Wallerstedt B, Behm L, et al. Towards evidence-based palliative care in nursing homes in Sweden: a qualitative study informed by the organizational readiness to change theory. Implement Sci, 2018, 13(1): 1.

11 Harris C, Garrubba M, Allen K, et al. Development, implementation and evaluation of an evidence-based program for introduction of new health technologies and clinical practices in a local healthcare setting. BMC Health Serv Res, 2015, 15(1): 575.

12 Graham ID, Logan J, Harrison MB, et al. Lost in knowledge translation: time for a map?. J Contin Educ Health Prof, 2006, 26(1): 13-24.

13 Weiner BJ, Amick H, Lee SY. Conceptualization and measurement of organizational readiness for change: a review of the literature in health services research and other fields. Med Care Res Rev, 2008, 65(4): 379.

14 Weiner BJ. A theory of organizational readiness for change. Implement Sci, 2009, 4(1): 67.

15 Zhou Min. Analysis and thinking on the status quo of nursing human resources allocation in our hospital. Modern Care, 2001, 7(12): 46-47.

16 Christl B, Harris MF, Jayasinghe UW, et al. Readiness for organisational change among general practice staff. Qual Saf Health Care, 2010, 19(5): e12.

17 Dogherty EJ, Harrison MB, Graham ID, et al. Turning knowledge into action at the point-ofcare: the collective experience of nurses facilitating the implementation of evidence-based practice. Worldviews Evid Based Nurs, 2013, 10(3): 129-139.

18 Neda M, Soodabeh J, Azadeh J, et al. Nursing faculties' knowledge and attitude on evidence-based practice. Iran J Nurs Midwifery Res, 2012, 17(7): 506-511.

19 Stroubouki TG. Translation of Evidence into Nursing and Health Care Practice. Nurse Educ Pract, 2013, 13(1): e10-e10.

20 Newhouse R, Dearholt S, Poe S, et al. Evidence-based Practice: A Practical Approach to Implementation. J Nurs Adm, 2005, 35(1): 35-40.

21 Shirey MR. Evidence-based Practice: How Nurse Leaders Can Facilitate Innovation. Nurs Adm Q, 2006, 30(3): 252-265. 